\title{
Comparison of three presentation methods in paired-associate learning'
}

\author{
JANET P, MOURSUND AND CATHERINE M. CHAPE
}

MICHIGAN STATE UNIVERSITY

Three methods of presentation of a 10-member paired-associate list were compared. These consisted of the standard anticipation method, a list available method, and a list study (simultaneous observation) method. An analysis of variance indicated significant differences among the three methods; inspection of the data suggests that these differences were due to significantly faster learning in the list study group.

In view of the large number of studies in the area of paired-associate learning, it is interesting to note the apparent lack of information on one rather important relationship-that between learning, on the one hand, and the way in which the learning is accomplished, on the other. Meaningfulness, similarity, complexity, and the like, have been studied intensely, but "method" is often taken for granted.

The standard anticipation method (hereafter designated as SAM) has been by far the most frequently utilized in paired-associate work, and recently a number of studies have compared this method with a "prompting" method (Cook \& Kendler, 1956; Lockheed, 1962; Hawker, 1964). Typical of these is that of Hawker, in which the materials were presented in a $S_{1} R_{1}, S_{1}, S_{2} R_{2}, S_{2}$, etc., pattern. Hawker found that prompting was superior to SAM only during the first block of trials.

Similar to the prompting method is that used by Battig (1961). His "blocking" presentation method presents all $\mathrm{S}-\mathrm{R}$ pairs one at a time, followed by a test trial of each of the S members alone. Surprisingly, the author reports that blocking resulted in significantly faster learning than SAM. Sidowski (1961) also utilized the test trial notion, and compared six different presentation methods. These were various combinations of prompting, anticipation, and confirmation techniques, plus a "simultaneous observation" method in which Ss studied the entire list of S-R pairs prior to the test trial. The simultaneous observation was second only to the "prompt S-R"' condition (similar to Hawker's method) in terms of a criterion of fewest number of errors per test-trial.

The line of research typified by the Martin et al study of associative strategies (1965) should also be mentioned here. In this and other studies (Schulz \& Lovelace, 1964; Hawker, 1965), a list-available method (LAM) has been used as a means of controlling response availability. In these studies, however, the main effort has been toward ascertaining interactive effects of other variables, such as meaningfulness, within the LAM structure, and no attempt has been made to compare LAM with SAM as main independent variables.
In the present study, the authors have attempted to compare learning speeds within the paired-associate framework; holding constant all variables except presentation method. In addition to SAM and LAM, a third presentation method was examined. This "list study method" (LSM) is equivalent to Sidowski's "simultaneous observation," and allows the $S$ to look at the whole list of S-R pairs for the same length of time as the total exposure time in the SAM or LAM, and then respond to the list of $S$ members in a test-trial. It was felt that the LSM most closely approximated types of learning situations met by the student in actual school experience, and thus the explication of any differences in learning emerging as a result of this presentation method might be useful in attempting to generalize present paired-associate findings to the school setting.

\section{Method}

Subjects. Ninety undergraduate students (mostly sophomores) who were taking their first course in psychology served as Ss. The Ss were randomly divided into three groups of 30 each, and each group performed under one of the three different experimental conditions.

Materials. Ten pairs of CVCs were used for the learning task. These pairs are shown in Table 1. As can be seen, there is considerable variability of $\mathrm{m}$ value within and among pairs, and in the degree of similarity between $S$ and $R$ members of the different pairs. It was felt that such heterogeneity would more closely approximate the variety of difficulty encountered in a naturalistic learning situation.

The materials were typed on belts of an MTA teaching machine. Four different random orders were used, so that the fifth trial order was the same as the first, etc. No pair was repeated with less than two other pairs intervening.

Anticipation Method (SAM): Materials were exposed for 3 sec. intervals in the following order: $S_{1}, S_{1} R_{1}$,

Table 1.

Ten S-R pairs constituting the learning task across three conditions.

\begin{tabular}{ll} 
S & R \\
\hline WEQ & VUD \\
FUP & KOQ \\
QOC & TOV \\
YAV & ZAJ \\
MUB & PEZ \\
DAX & XAP \\
JIZ & FEG \\
BEH & HUW \\
TOJ & QOL \\
XIF & CEF \\
\hline
\end{tabular}




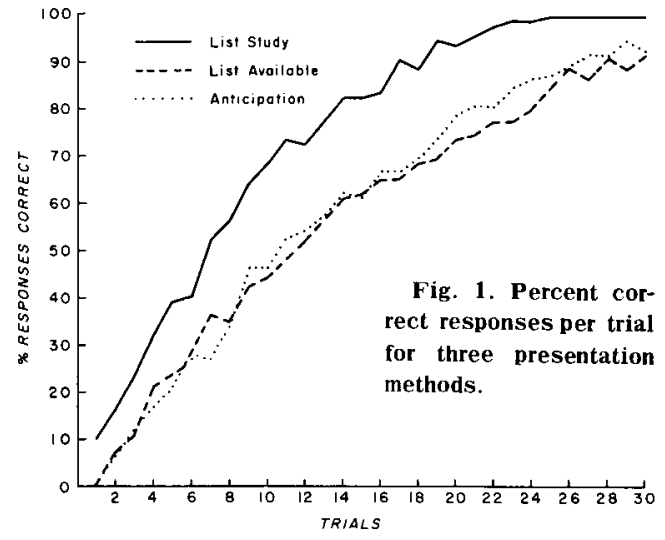

$\mathrm{S}_{2}, \mathrm{~S}_{2} \mathrm{R}_{2} \ldots$ Ss were instructed to spell out the appropriate $\mathbf{R}$ member whenever an $\mathbf{S}$ member was presented alone. There was a 6 sec. rest period between trials.

List Available Method (LAM): This was identical to SAM except that the $S$ was provided with a cardboard sheet on which were printed, in random order different from the four orders used on the presentation belt, the $10 \mathrm{R}$ members. Ss were told that the list contained all of the correct responses, and that they might use it if they wished.

List Study Method (LSM): A list of the S-R pairs was printed on cardboard and given to the $S$ for $30 \mathrm{sec}$. Following this period, the teaching machine was used to present each $\mathrm{S}$ member for 3 sec. during which the $\mathrm{S}$ was to spell out the corresponding $\mathbf{R}$ member. No confirmation of right or wrong responses was given during this test-trial.

It can be seen that the total exposure time for $\mathrm{S}$ and $R$ members per trial was equal across SAM and LSM conditions. Ss saw the S-R pairs for a total of $30 \mathrm{sec}$. and the $S$ members alone for $30 \mathrm{sec}$. The LAM condition involved an undetermined increase in exposure time for the $\mathrm{R}$ members; no effort was made to measure the extent to which Ss made use of the lists.

Procedure. Ss were instructed to learn to give the appropriate response to each of the 10 stimuli; specific instructions varied according to the condition under which the $S$ was working. Criterion was defined as two correct trials; Ss were run to criterion or through 30 trials, whichever occurred sooner.

\section{Results and Discussion}

Data were recorded in two ways: one in which partially correct answers were taken into account, and the other in which only "right" or "wrong" answers were considered. The two methods of scoring yielded almost identical curves, and therefore only the former was utilized in the final analyses.

Figure 1 shows the learning curves produced by averaging the percent correct responses per trial within each of the three groups. As can be seen, the Anticipation and the List Available groups behaved very similarly, while the curve for the List Study group is noticeably higher and steeper. A repeated measures analysis of variance yields highly signif- icant $\mathrm{F}$ ratios for both the Methods main effect $(F=14.1$, $\mathrm{df}=2 / 87, \mathrm{p}<.01$ ) and the Trials by Methods interaction $(F=3.6, d f=58 / 2523, p<.01)$. Inspection of Fig. 1 suggests strongly that the significance arises out of the difference between the LSM curve and the other two; the LAM and SAM curves are almost superimposed one upon the other.

It seems clear that the availability of the list of possible responses did not simplify the learning task to any appreciable degree. (Interestingly, however, Ss' verbal reports indicated that they felt the list of responses did help them in the task.) The List Study condition produced significantly faster learning. It has been suggested (Cook \& Kendler, 1956) that the List Study condition may be superior in that it allows for a shorter gap between presentation of an $S_{n} R_{n}$ pair and the $S_{n}$ test. It is also possible, as a corollary of this notion, that the $S$ uses the list to set up for himself a relatively large number of short $S_{n} R_{n}$ exposures, thus utilizing a sort of psuedo-spaced-practice paradigm. On the other hand, exactly the opposite may be occurring: e.g., having the entire list available for $30 \mathrm{sec}$. may allow the $S$ to concentrate on only a few of the items until they have been learned, thus actually involving himself in learning several short lists, sequentially, rather than one long list.

Whatever the mechanism behind it, the superiority of the List Study Method does seem to suggest one rather strong conclusion: that the learner himself may be the best "pacer" of his learning process. This notion has been introduced to an increasing degree in our public and private schools; it may well be an important next step for the laboratory scientist to find out just what these pacing algorithms are and in what manner they are acquired by the learner.

\section{References}

Battig, W. F. Comparison of anticipation and recall methods of paired-associate learning. Psychol. Rep., 1961, 9, 59-65.

Cook, J. O., \& Kendler, T. S. A theoretical model to explain some paired-associate learning data. In G. Finch and F. Cameron (Eds.), Symposium on air force human engineering, personnel, and training research. Washington, D. C.: Nat. Acad. Sci.-Nat. Res. Coun., 1956. Pp. 90-98. (Publ. 455)

Hawker, J. R. The effects of training procedure, response availability, and response meaningfulness in multiple-choice pairedassociate learning. Psychon. Sci., 1965, 3, 331-332.

Hawker, J. R. The influence of training procedure and other task variables in paired-associate learning. $J$. verbal Learn. verbal Behav., 1964, 3, 70-76.

Lockhead, G. R. Methods of presenting paired-associates. J. verbal Learn. verbal Behav., 1962, 1, 62-65.

Martin, C. J., Cox, D. L., \& Boersma, F. J. The role of associative strategies in the acquisition of P-A material: An alternate approach to meaningfulness. Psychon. Sci., 1965, 3, 463-464.

Schulz, R. W., \& Lovelace, E. A. Meaningfulness and the associative phase of palred-associate learning: A methodological consideration. Psychon. Sci., 1964, 1, 37-38.

Sidowski, J. B. Prompting and confirmation variables in verbal learning. Psychol. Rep., 1961, 8, 401-406.

\section{Note}

1. This study was carried out under the auspices of the Human Learning Research Institute, Michigan State University. 